\title{
Is there a best conventional material for restoring posterior primary teeth? A network meta-analysis
}

\section{Carine Weber PIRES(a) \\ Diessica PEDROTT|(b) \\ Tathiane Larissa LENZI (b) \\ Fabio Zovico Maxnuck SOARES(c) \\ Patricia Klarmann ZIEGELMANN(d) \\ Rachel de Oliveira ROCHA ${ }^{(e)}$}

\footnotetext{
(a) Centro Universitário da Serra Gaúcha - FSG, School of Dentistry, Caxias do Sul, RS, Brazil.

(b) Universidade Federal de Santa Maria - UFSM, School of Dentistry, Graduate Program in Dental Science, Santa Maria, RS, Brazil.

(c) Universidade Federal de Santa Maria UFSM, School of Dentistry, Department of Restorative Dentistry, Santa Maria, RS, Brazil.

(d) Universidade Federal do Rio Grande do Sul - UFRGS, School of Dentistry, Epidemiology Graduate Program, Porto Alegre,RS, Brazil.

(e) Universidade Federal de Santa Maria UFSM, School of Dentistry, Santa Maria, RS, Brazil.
}

\begin{abstract}
This study aimed to compare the longevity of different conventional restorative materials placed in posterior primary teeth. This systematic review was conducted following the PRISMA statement and registered in PROSPERO (CRD42016035775). A comprehensive electronic search without date or language restrictions was performed in PubMed/MEDLINE, Cochrane Central Register of Controlled Trials, Scopus, Turning Research Into Practice (TRIP) and Clinical Trials databases up to January 2017, selecting randomized clinical trials that assessed the longevity of at least two different conventional restorative materials performed in primary molars. Seventeen studies were included in this systematic review. Pairwise and network meta-analyses were performed and relative risks and 95\% confidence intervals (CI) calculated. Two reviewers independently selected the studies, extracted the data, and assessed the risk of bias. Restorations of primary molars with conventional glass ionomer cement showed increased risk of failure than compomer, resin-modified glass ionomer cement, amalgam, and composite resin. Risk of bias was low in most studies (45.38\% of all items across studies). Pediatric dentists should avoid conventional glass ionomer cement for restoring primary molars.
\end{abstract}

Keywords: Dental Materials; Evidence-Based Dentistry; Pediatric Dentistry.

\section{Introduction}

certify that they have no commercial or associative interest that represents a conflict of interest in connection with the manuscript.

Corresponding Author:

Rachel de Oliveira Rocha

E-mail: rachelrocha@smail.ufsm.br

https://doi.org/10.1590/1807-3107bor-2018.vol32.0010

Submitted: July 13, 2017

Accepted for publication: December 13, 2017

Last revision: January 11, 2018
Although the prevalence of dental caries has decreased, advanced caries lesions remain a frequent problem that can negatively impact the quality of life of children. ${ }^{1}$ Therefore, dental fillings are still routinely placed in daily pediatric dental clinics. Restorative therapy has many benefits such as restoring the tooth structure and, thus, preventing teeth from shifting and protecting the dental pulp. ${ }^{2}$

Conventional restorative materials available for restoring posterior primary teeth include amalgam (AM), conventional glass ionomer cement (GIC), resin-modified glass ionomer cement (RMGIC), high-viscosity glass ionomer cement (HVGIC), compomer (CP), and composite resin (CR). ${ }^{3}$ Although amalgam has been considered the gold standard in restorative dentistry ${ }^{4}$, its use has decreased mainly because of the potential toxicity of mercury and the need to remove healthy tooth structure during preparation. ${ }^{5}$ Therefore, restorative materials with adhesive properties 
have been widely used since they are in line with the concept of Minimally Invasive Dentistry, are easy to handle and provide functional performance besides meeting patients' esthetics demands. ${ }^{3}$

However, there is still inconsistency regarding the choice of the best conventional restorative material for restoring carious primary teeth. ${ }^{6}$ Direct evidence from high quality randomized clinical trials should be used when possible. Otherwise, indirect comparisons from randomized clinical trials might be necessary. ${ }^{7}$ Therefore, the aim of this systematic review and network meta-analysis was to evaluate the clinical performance of different conventional restorative materials placed in posterior primary teeth. The hypothesis tested was that there would be no difference in longevity of restorative materials in primary dentition.

\section{Methodology}

This study was conducted according to a Preferred Reporting Items for Systematic Reviews and Meta-Analysis (PRISMA) guidelines ${ }^{8}$ and recorded in the International Prospective Register of Systematic Review (PROSPERO- CRD42016035775).

\section{PICO framework}

The following research question was formulated to address the literature and outline the search strategy: Is there a best conventional material for restoring posterior primary teeth?

a. Population: occlusal or occluso-proximal restorations placed in primary molars;

b. Intervention: use of any restorative material according to conventional treatment;

c. Comparison: Amalgam, compomer, composite resin, conventional glass ionomer cement, resin-modified glass ionomer cement, highviscosity glass ionomer cement or reinforced glass ionomer cement;

d. Outcomes: survival rate (number of restorative failures based on clinical criteria such as FDI and USPHS).

\section{Search strategy}

A comprehensive literature search was undertaken through the PubMed/MEDLINE, Cochrane Central Register of Controlled Trials (CENTRAL), Scopus and Turning Research Into Practice (TRIP) databases on January 2017 to identify studies that evaluated the clinical performance of conventional dental materials placed in primary molars. The search was conducted with no publication year or language restriction using a combination of controlled vocabulary and free text terms based on the search strategy for the PubMed/MEDLINE database as follow:

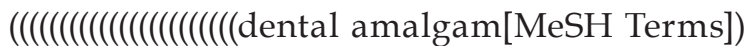
OR dental amalgam) OR amalgam) OR composite resins[MeSH Terms]) OR composite resins) OR composite resin*) OR resin composite*) OR compomers[MeSH Terms]) OR compomers) OR compomer) OR polyacid-modified composite resin*) OR polyacid modified composite resin*) OR resin*) OR glass ionomer cements[MeSH Terms]) OR glass ionomer cements) OR glass ionomer cement) OR glass polyalkenoate cement*) OR resin-modified glass ionomer cement*) OR high viscous glass ionomer cement*) OR high viscosity glass ionomer cement)))

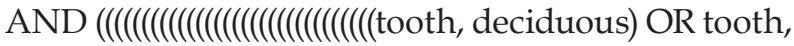
deciduous[MeSH Terms]) OR deciduous tooth) OR deciduous teeth) OR primary tooth) OR primary teeth) OR primary dentition*) OR deciduous dentition*) OR milk tooth) OR milk teeth) OR baby tooth) OR baby teeth) AND dental restoration, permanent[MeSH Terms]) OR dental restoration, permanent) OR dental restoration*) OR dental restoration permanent) OR dental filling permanent) OR permanent dental filling*) OR dental permanent filling*) AND posterior restoration*) OR class II cavities) OR class II) OR proximal lesions) OR approximal lesions) OR (occlu* AND proximal)) OR class I) OR class I cavities) OR occlusal lesions))) AND (((((clinical[Title/Abstract] AND trial[Title/Abstract]) OR clinical trials[MeSH Terms] OR clinical trial[Publication Type] OR random*[Title/Abstract] OR random allocation[MeSH Terms] OR therapeutic use[MeSH Subheading]))))))

A sensitive search strategy was adapted for the CENTRAL, Scopus and TRIP databases. To reduce publication bias, unpublished documents through the ClinicalTrials.gov database were checked. The results 
of searches of various databases were cross-checked to locate and eliminate duplicates using Review Manager Software 5.1 (Nordic Cochrane Centre, Cochrane Collaboration).

\section{Selection criteria}

Titles and abstracts were reviewed independently by two authors (CWP and DP) and selected for further review if they met the inclusion criteria: clinical trials that compared the longevity of at least two different conventional restorative materials placed in posterior primary teeth. Any disagreement was firstly solved by discussion between the two reviewers. If disagreements remained, a third author (TLL) was consulted. The interexaminer agreement was calculated (Kappa $=0.96)$, indicating excellent agreement. To retrieve all relevant articles, the reviewers screened the reference lists of the included articles.

A final decision about inclusion was made based on the full-text of the potentially relevant studies in accordance with the exclusion criteria: non-random allocation of subjects; follow-up of less than 12 months; dropout higher than $30 \%$; absence of similar follow-up for groups evaluated in a similar way; no computable data for both groups; did not perform conventional treatment - such as Atraumatic Restorative Treatment (ART), comparison of conventional filling material with any type of preformed crowns, and sample containing teeth that received endodontic treatment prior to the restorative treatment.

\section{Data extraction}

The selected full-text articles were assessed (CWP and DP) using a standardized form (Office Excel 2013 Software, Microsoft Corporation, Redmond, WA, USA) and the relevant data were extracted independently. From each study, the following data were recorded: demographic setting (year, country), study design, type of cavity, characteristics and size of the population, age range of participants, number of teeth/restorations, follow-up period, evaluation intervals, dropout rate, commercial brand and manufacturer of the materials, operative field isolation method, number of operators and evaluation criteria. The longevity of the materials was recorded as the number of failed restorations.

\section{Risk of bias assessment}

The two reviewers independently assessed $($ Kappa $=1.00)$ therisk of bias using the assessment forms specific for each study design. ${ }^{9}$ The criteria were divided into seven domains as follows: selection bias (sequence generation, allocation concealment), performance and detection bias (blinding of participants, personnel, and outcome assessment), attrition bias (incomplete outcome data), and reporting bias (selective outcome reporting). The evaluation of the studies was performed by rating each of the study criteria as "low risk", "high risk", or "unclear risk" (no information or uncertainty over the potential for bias). If needed, authors were contacted via e-mail (at least two attempts were made) for missing or unclear information.

\section{Statistical analysis}

The data were analyzed using traditional pairwise meta-analysis followed by network meta-analysis. ${ }^{10}$ The network meta-analysis was based on a binomial model with log link function. ${ }^{11}$ Therefore, the effect-size measure estimated was relative risk. ${ }^{9}$ The GIC was considered the baseline treatment. Both fixed effect and homogeneous variance random effects models were considered. The choice of model and goodness of fit was made based on the DIC (Deviance Information Criterion). Models were adjusted using Markov Chain Monte Carlo methods with non-informative priors. Convergence was assessed by trace plots and inconsistency by split node method. ${ }^{12}$

\section{Results}

\section{Study selection}

The search strategy identified 1,561 potentially relevant records, excluding duplicates. Two ongoing trials were identified. After screening titles and abstracts, 48 studies were retrieved to obtain detailed information. Another 10 studies were identified in reference lists of related reviews. From the 58 full-text articles, 2 studies presented the same sample ${ }^{13,14}$ and, thus, the one with shorter follow-up period was excluded. ${ }^{13}$ Finally, 17 randomized controlled trials (RCTs) met the eligibility criteria and were included in the systematic review. The flow chart in Figure 1 summarizes the process of study selection and the reasons for exclusions. 


\section{Characteristics of the included studies}

The main characteristics of the included papers are presented in the Table 1 . There were six RCTs using parallel groups, ${ }^{15,16,17,18,19,20}$ one $\mathrm{RCT}^{21}$ using split-mouth design in most samples and ten RCTs using split-mouth for all samples. . $^{1422,23,24,25,26,27,28,29,30}$ The follow-up period ranged from 12 to 60 months; however, $47.06 \%$ of the studies had 24 months of follow-up. Only two studies used FDI as evaluation criteria. ${ }^{15,30}$

Of the total studies, $41.2 \%$ evaluated Class I and II restorations in primary teeth ${ }^{14,16,20,23,25,26,29}$ and $47.06 \%$ used rubber dam isolation. ${ }^{14,15,16,17,20,22,23,29,30}$ Three clinical studies compared $\mathrm{AM}$ and $\mathrm{CR}_{,}^{22,23,24} \mathrm{AM}$ and $\mathrm{CP}^{17,27,28}$ or RMGIC, CP and CR restorations ${ }^{14,15,30}$. CR and $\mathrm{RMGIC}^{19,20}$ or $\mathrm{CP}$ and $\mathrm{CR}^{16,29}$ were investigated by two different studies. There was only one article that compared restorations performed with GIC and $\mathrm{RMGIC}^{21} \mathrm{AM}$ and $\mathrm{GIC}^{25} \mathrm{AM}$ and $\mathrm{RMGIC}_{1}^{18}$ and $\mathrm{CP}$ and GIC. ${ }^{26}$ Moreover, some studies did not report the commercial brand of the adhesive used.

\section{Risk of bias}

The final assessment of the risk of bias for the included studies is displayed in Table 2. Risk of bias was low in most studies $(45.38 \%$ of all items across studies). Six studies did not describe the method used to generate the random sequence, ${ }^{17-19,23-25}$ leading to unclear risk of bias in this domain. Moreover, all studies had unclear risk of bias regarding the allocation concealment. Only studies comparing AM with tooth-colored conventional fillings had high risk of bias in blinding of participants domain. 17,18,2,23,24,25,27,28 All studies were classified as high risk considering blinding of operators and evaluators, since their blinding is not possible when performing and evaluating dental restorations.

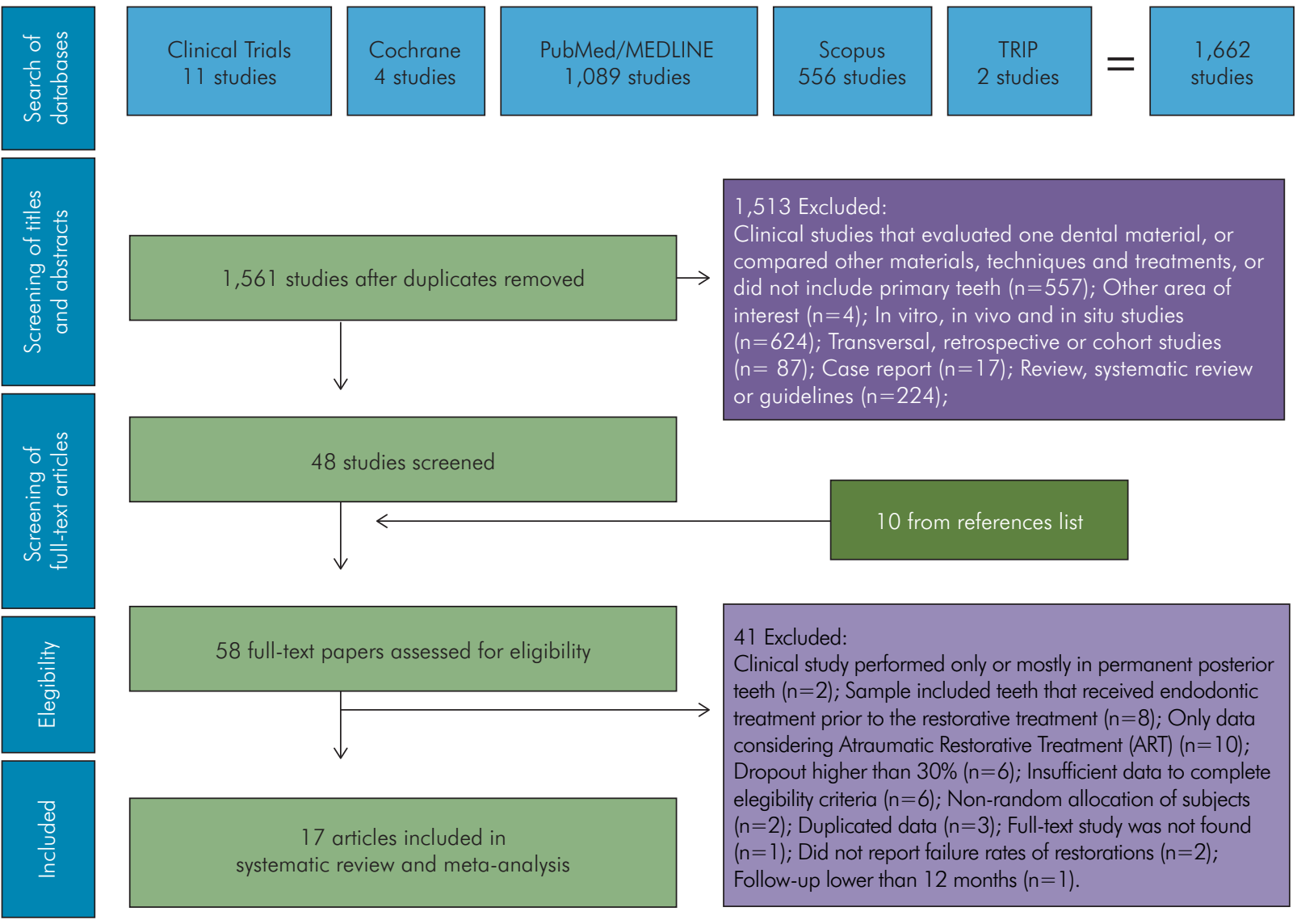

Figure 1. PRISMA flow diagram outlining the study selection process. 


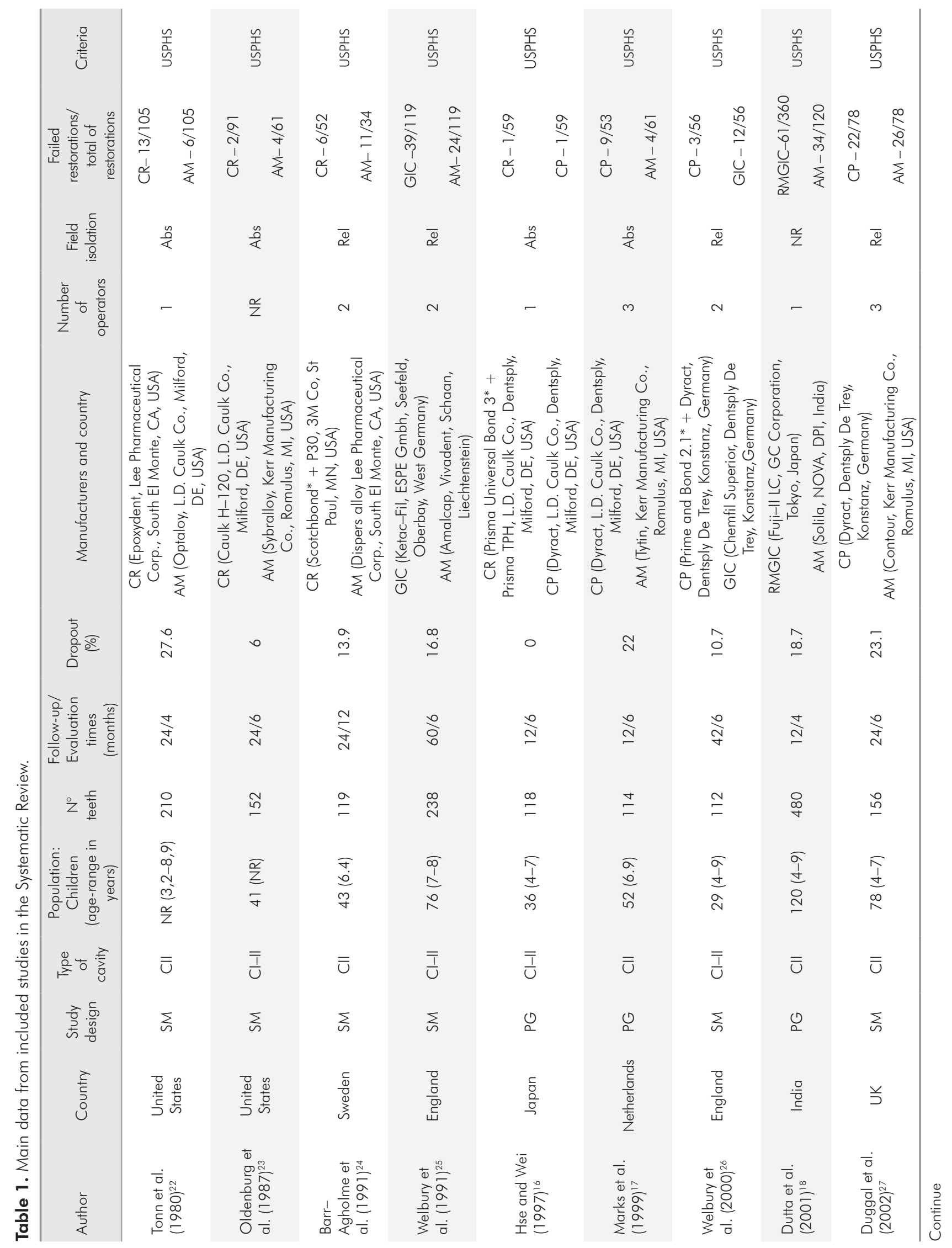




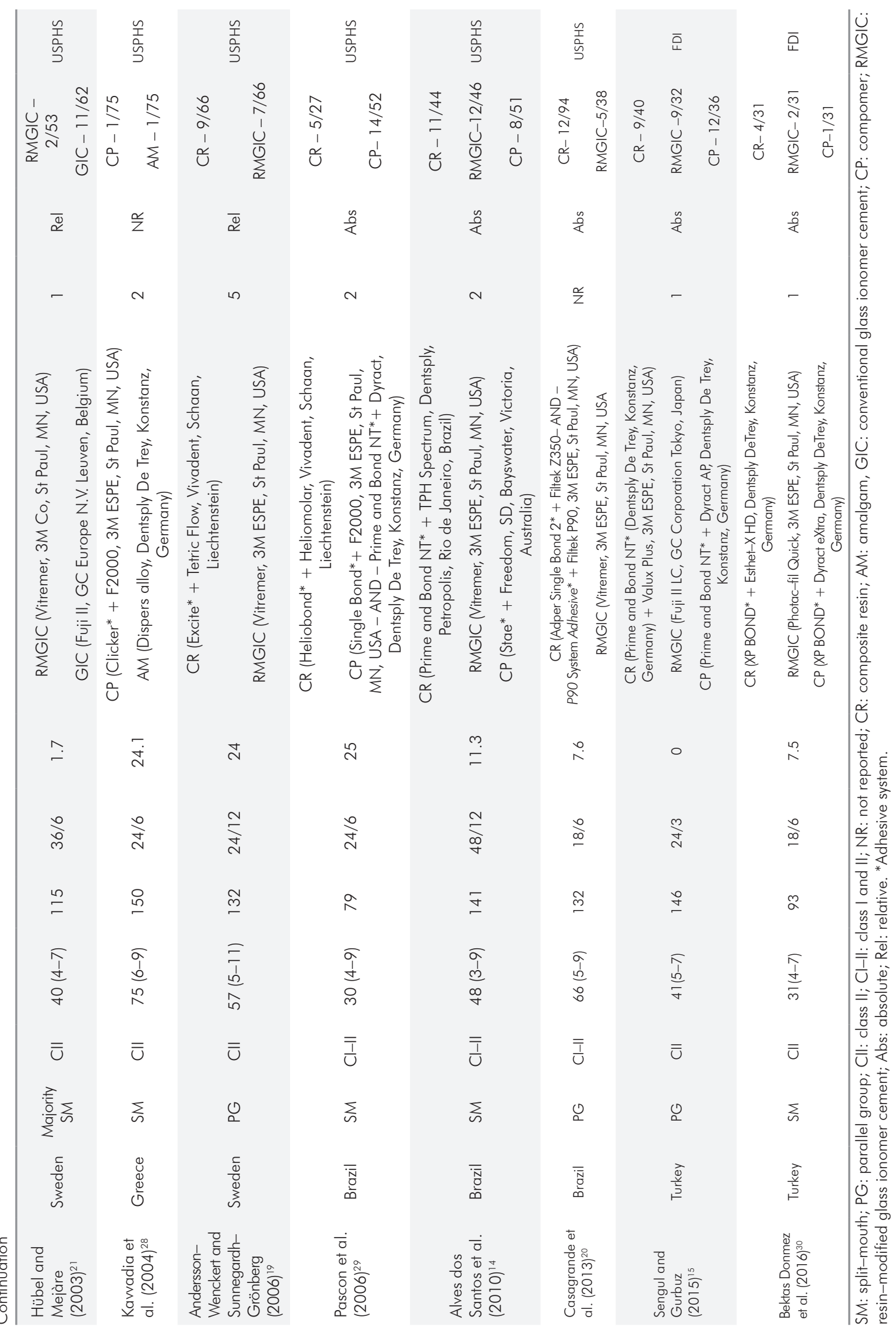


Table 2. Risk of bias of the included studies.

\begin{tabular}{|c|c|c|c|c|c|c|c|}
\hline Author & $\begin{array}{c}\text { Random } \\
\text { sequence } \\
\text { generation }\end{array}$ & $\begin{array}{c}\text { Allocation } \\
\text { concealment }\end{array}$ & $\begin{array}{l}\text { Blinding of } \\
\text { participants }\end{array}$ & $\begin{array}{l}\text { Blinding of } \\
\text { personnel }\end{array}$ & $\begin{array}{l}\text { Blinding of } \\
\text { outcome } \\
\text { assessment }\end{array}$ & $\begin{array}{l}\text { Incomplete } \\
\text { outcome } \\
\text { data }\end{array}$ & $\begin{array}{l}\text { Selective } \\
\text { reporting }\end{array}$ \\
\hline Tonn et al. $(1980)^{22}$ & low & unclear & high & high & high & low & low \\
\hline Oldenburg et al. $(1987)^{23}$ & unclear & unclear & high & high & high & low & low \\
\hline Barr-Agholme et al. $(1991)^{24}$ & unclear & unclear & high & high & high & low & low \\
\hline Welbury et al. (1991)25 & unclear & unclear & high & high & high & low & low \\
\hline Hse and Wei $(1997)^{16}$ & low & unclear & low & high & high & low & low \\
\hline Marks et al. (1999) ${ }^{17}$ & unclear & unclear & high & high & high & low & low \\
\hline Welbury et al. $(2000)^{26}$ & low & unclear & low & high & high & low & low \\
\hline Dutta et al. $(2001)^{18}$ & unclear & unclear & high & high & high & low & low \\
\hline Duggal et al. $(2002)^{27}$ & low & unclear & high & high & high & low & low \\
\hline Hübel and Mejàre (2003) 21 & low & unclear & low & high & high & low & low \\
\hline Kavvadia et al. $(2004)^{28}$ & low & unclear & high & high & high & low & low \\
\hline $\begin{array}{l}\text { Andersson-Wenckert and } \\
\text { Sunnegardh-Grönberg }(2006)^{19}\end{array}$ & unclear & unclear & low & high & high & low & low \\
\hline Pascon et al. $(2006)^{29}$ & low & unclear & low & high & high & low & low \\
\hline Alves dos Santos et al. $(2010)^{14}$ & low & unclear & low & high & high & low & low \\
\hline Casagrande et al. $(2013)^{20}$ & low & unclear & low & high & high & low & low \\
\hline Sengul and Gurbuz (2015) ${ }^{15}$ & low & unclear & low & high & high & low & low \\
\hline Bektas Donmez et al. $(2016)^{30}$ & low & unclear & low & high & high & low & low \\
\hline
\end{tabular}

\section{Network meta-analysis}

Nine possible direct pair-wise comparisons were performed between the five restorative materials (results not shown). The relative risk was significantly higher for GIC when compared with CP ( $R R=4.00 ; 95 \%$ CI: 1.19-13.41), RMGIC ( $R R=4.70 ; 95 \%$ CI: 1.09-20.27) and AM ( $R R=1.62$; 95\% CI: 1.05-2.52). Only the comparison between GIC and $\mathrm{CR}$ did not have direct evidence. In addition, the relative risk was significantly smaller for RMGIC when compared with AM (RR=0.60; 95\% CI: 0.42-0.86).

A network analysis of evidence comparing the five restorative materials (CR, $\mathrm{AM}, \mathrm{GIC}, \mathrm{CP}$ and RMGIC) was performed for all comparison pairs. The network is displayed in Figure 2.

The homogeneous variance random effects model show the best fit according to DIC values (62.98 against 64.44). The results from this model and using the split node method are shown in Table 3. The p-value is for inconsistencies between direct and indirect evidence for each comparison pair in a closed loop of evidence. All the $\mathrm{p}$-values are high indicating no inconsistency justifying the use of the mixed treatment comparison (MTC) model. Results from this model show that the relative risk is significantly higher for GIC when compared

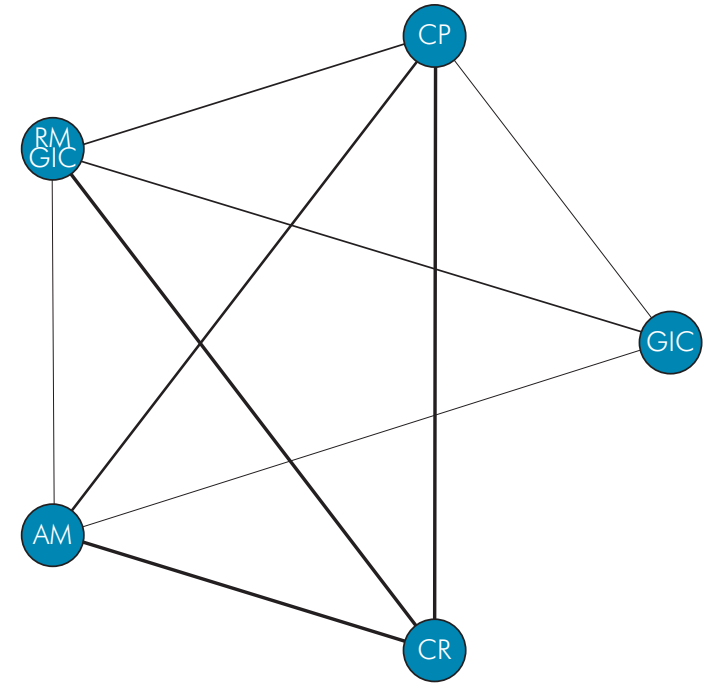

Restorative materials: CR: composite resin; AM: amalgam; GIC: conventional glass ionomer cement; CP: compomer; RMGIC: resin-modified glass ionomer cement.

Figure 2. Comparisons network of conventional restorative materials placed in primary teeth. The width of lines connecting each pair of treatment is proportional to the number of trials comparing the treatments.

with $C P$ ( $R R=2.64$, 95\% CI: 1.29-6.27), RMGIC ( $R R=3.25$, 95\% CI: 1.58-7.96), AM (RR=2.25, 95\% CI: 1.17-5.35) and CR (RR=3.27; 95\% CI: 1.55-8.13). 
Table 3. Mixed treatment comparison (MTC) model comparing all the direct restorative materials used in primary teeth.

\begin{tabular}{lcccc}
\hline Pair-wise comparison & Direct comparison & Indirect comparison & MTC & p-value \\
\hline GIC-CP & $4.67(1.12,25.92)$ & $2.18(0.86,6.12)$ & $2.64(1.29,6.27)$ & 0.38 \\
GIC-RMGIC & $5.94(1.22,48.80)$ & $2.87(1.15,8.01)$ & $3.30(1.58,7.96)$ & 0.44 \\
GIC-AM & $1.65(0.62,4.33)$ & $4.22(1.35,16.52)$ & $2.25(1.17,5.35)$ & 0.19 \\
GIC-CR & - & - & $3.27(1.55,8.13)$ & $1.23(0.72,2.16)$ \\
CP-RMGIC & $0.93(0.39,2.15)$ & $1.80(0.73,4.96)$ & $0.85(0.51,1.49)$ & 0.25 \\
CP-AM & $1.31(0.62,3.06)$ & $0.60(0.29,1.21)$ & $1.23(0.75,2.07)$ & 0.11 \\
CP-CR & $1.11(0.53,2.26)$ & $1.78(0.62,5.99)$ & $0.69(0.40,1.23)$ & 0.43 \\
RMGIC-AM & $0.61(0.21,1.73)$ & $0.76(0.36,1.58)$ & $1.00(0.61,1.64)$ & 0.73 \\
RMGIC-CR & $1.06(0.57,1.93)$ & $0.88(0.27,2.84)$ & $1.44(0.84,2.41)$ & 0.79 \\
AM-CR & $1.53(0.71,3.59)$ & $1.35(0.57,2.79)$ & & \\
\hline
\end{tabular}

Table 4. Ranking of materials according to probability of failure.

\begin{tabular}{lccccc}
\hline Materials & $\begin{array}{c}\text { Position } \\
1^{*}\end{array}$ & $\begin{array}{c}\text { Position } \\
2\end{array}$ & $\begin{array}{c}\text { Position } \\
3\end{array}$ & $\begin{array}{c}\text { Position } \\
4\end{array}$ & $\begin{array}{c}\text { Position } \\
5^{* *}\end{array}$ \\
\hline GIC & 0.0005 & 0.0009 & 0.0023 & 0.0104 & 0.9856 \\
CP & 0.0898 & 0.1875 & 0.4849 & 0.2334 & 0.0042 \\
RMGIC & 0.4472 & 0.3531 & 0.1535 & 0.0451 & 0.0009 \\
AM & 0.0265 & 0.0674 & 0.2204 & 0.6771 & 0.0083 \\
CR & 0.4358 & 0.3909 & 0.1385 & 0.0338 & 0.0008 \\
\hline
\end{tabular}

*Smaller probability of restoration failure; "Larger probability of restoration failure.

Table 4 presents the ranking of treatments according to their probability of higher longevity. The order from lowest to highest probability of failure was RMGIC, CR, CP, AMG and GIC. The probability of failure of GIC was 0.9856 .

\section{Discussion}

There is a lack of strong evidence establishing the most suitable conventional material for restoring primary molars. Therefore, the present systematic review and network meta-analysis aimed to answer the following question: "Is there a best conventional material for restoring posterior primary teeth?". A previous similar systematic review addressed this question. ${ }^{6}$ However, the study included only three trials comparing four different types of materials in the primary dentition: crown restoration (esthetic and stainless steel crowns), RMIGIC, AM and $\mathrm{CP}$; no significant differences were found for the outcomes assessed.

Our network meta-analysis found that GIC had a higher risk of failure compared to all the other conventional restorative materials. This is an important finding since GIC has been widely used for restoration of primary teeth because of its several advantages including fluoride release, chemical bonding to enamel and dentin, tooth preparation with minimal removal of sound structure, biocompatibility and being user-friendly. ${ }^{21,31,32}$ Nevertheless, this material presents disadvantages such as low wear resistance and flexural strength. To overcome the brittle nature of this cement and improve its physical properties, modifications on its original composition were developed, such as the RMGIC. ${ }^{32,33}$

One included study compared the clinical performance of GIC and RMGIC restorations. In the 3-year follow-up study by Hübel and Mejàre, ${ }^{21}$ the risk of failure of a class II restoration was more than five times higher with GIC (Fuji II, GC) than with RMGIC (Vitremer, 3M ESPE). This is in accordance with a previous systematic review that did not recommend GIC for class II cavities in primary molars and showed that RMGIC presented better performance in small to moderate size proximal restorations. ${ }^{34}$ Moreover, the three studies comparing 
GIC with other materials ${ }^{21,25,26}$ used conventional GIC (Chemfil Superior, Ketac Fil, Fuji II). Therefore, more clinical studies comparing high-viscosity GIC with other conventional restorative materials are needed, since this material is a viable option for restoring primary molars..$^{35}$ It is important to highlight that high-viscosity GIC used following the ART approach have shown similar survival rates in primary molars compared with conventional technique (drilling and restoring and/or hand excavation associated with resin composite, amalgam, or compomer). ${ }^{36,37}$

The follow-up period ranged from 12 to 60 months, but most studies followed the patients for 24 months. Therefore, we tried to pool the follow-up periods for analysis in an attempt to not jeopardize any material with longer follow-up. However, the pooling was not possible, which was considered a limitation of this systematic review. Since there was no randomized clinical trial comparing GIC and $\mathrm{CR}$ restorations, indirect comparisons by means of a mixed treatment comparisons meta-analysis were carried out. The pair-wise comparisons of GIC vs. RMGIC ${ }^{21}$ and CR vs. RMGIC ${ }^{19,20}$ showed higher risk of failure for GIC compared to CR. This finding is in line with a retrospective study with 4 years of follow-up that found that CR restorations in primary teeth presented lower failure rate than GIC ones. ${ }^{38}$

Although the MTC model did not found a significantly difference among CP, RMGIC, AM, and $\mathrm{CR}$, the ranking based on probability of failures showed that RMGIC and RC are in the best position, with lower probability, $\mathrm{CP}$ and $\mathrm{AM}$ in intermediate position, and GIC in the worst position, consistent with the network meta-analysis findings. CR has a wide range of applications in Dentistry. As an esthetic and versatile material, ${ }^{39}$ it presents a lower annual failure rate $(9.5 \%)$ in posterior restorations compared to other esthetic materials. ${ }^{38}$ Furthermore, $\mathrm{CR}$ allows the preservation of tooth structure because of its adhesive properties. ${ }^{40}$ On the other hand, RMGIC retains the advantages of GIC (fluoride release, biocompatibility, physiochemical bonding to the tooth, favorable thermal expansion and contraction) but present better fracture and wear resistance than GIC. ${ }^{32}$
Regarding commercial brands, Vitremer (3M ESPE, St Paul, MN, USA) was used in $57.1 \%$ of the RCTs evaluating RMGIC restorations. Dyract (Dentsply De Trey, Konstanz, Germany) was the material of choice in $77.8 \%$ of RCTs that used CP. The brands of AM, CR and GIC varied considerably among studies. It is important to consider the variability of the selected studies, including different materials, types of cavities, sample sizes, follow-up periods, restorative techniques and operative field isolation techniques. However, a systematic review has showed that the isolation technique does not influence the longevity of restorations. ${ }^{41}$ Furthermore, in all included studies, trained operators performed the restorative procedures.

Our review included clinical studies from the 1980s to 2016, and thus, some of the restorative materials evaluated are no longer available. Moreover, the majority of the studies showed unclear or high risk of bias. Some parameters that could interfere in risk of bias analysis were not reported. Nevertheless, random sequence generation was reported in the majority of the studies. Finally, blinding is not feasible when comparing different restorative materials and can be considered an inherent characteristic of the study design.

Therefore, further randomized controlled clinical investigations are needed to compare different materials and techniques, using standardized methodology to evaluate the success of restorative treatments in primary dentition.

\section{Conclusions}

Based on this study's results, the following conclusions can be made:

Conventional glass ionomer cement in primary molars conventional restorations had higher risk of failure than other restorative materials.

There is no advantage among restorative treatments using compomer, resin-modified glass ionomer cement, amalgam and composite resin. Thus, clinical decision-making will depend on the ability of the professional, the individuality of the case, and the patient's wish. 


\section{References}

1. Ramos-Jorge J, Alencar BM, Pordeus IA, Soares ME, Marques LS, Ramos-Jorge ML et al. Impact of dental caries on quality of life among preschool children: emphasis on the type of tooth and stages of progression. Eur J Oral Sci. 2015 Apr;123(2):88-95. https://doi.org/10.1111/eos.12166

2. American Academy of Pediatric Dentistry. Guideline on restorative dentistry. Pediatr Dent. 2016 Oct;38(6):250-62.

3. Dhar V, Hsu KL, Coll JA, Ginsberg E, Ball BM, Chhibber $\mathrm{S}$ et al. Evidence-based update of pediatric dental restorative procedures: dental materials. J Clin Pediatr Dent. 2015;39(4):303-10. https://doi.org/10.17796/1053-4628-39.4.303

4. Mickenautsch S, Yengopal V, Baneriee A. Atraumatic restorative treatment versus amalgam restoration longevity: a systematic review. Clin Oral Investig. 2010 Jun;14(3):233-40. https://doi.org/10.1007/s00784-009-0335-8

5. Fuks AB. The use of amalgam in pediatric dentistry: new insights and reappraising the tradition. Pediatr Dent. 2015 Mar-Apr;37(2):125-32.

6. Yengopal V, Harneker SY, Patel N, Siegfried N. Dental fillings for the treatment of caries in the primary dentition. Cochrane Database Syst Rev. 2016;17;10:CD004483. https://doi.org/10.1002/14651858.CD004483.pub3

7. Glenny AM, Altman DG, Song F, Sakarovitch C, Deeks JJ, D'Amico R et al.; International Stroke Trial Collaborative Group. Indirect comparisons of competing interventions [iii-iv.]. Health Technol Assess. 2005 Jul;9(26):1-134. https://doi.org/10.3310/hta9260

8. Hutton B, Salanti G, Caldwell DM, Chaimani A, Schmid $\mathrm{CH}$, Cameron $\mathrm{C}$ et al. The PRISMA extension statement for reporting of systematic reviews incorporating network meta-analyses of health care interventions: checklist and explanations. Ann Intern Med. 2015 Jun;162(11):777-84. https://doi.org/10.7326/M14-2385

9. Higgins JP, Sally G. Cochrane handbook for systematic reviews of interventions Version 5.1.0 [Updated March 2011]. The Cochrane Collaboration 2011. Available at: http://handbook.cochrane.org/handbook

10. Jansen JP, Crawford B, Bergman G, Stam W. Bayesian meta-analysis of multiple treatment comparisons: an introduction to mixed treatment comparisons. Value Health. 2008 Sep-Oct;11(5):956-64. https://doi.org/10.1111/j.1524-4733.2008.00347.x

11. Lu G, Ades AE. Combination of direct and indirect evidence in mixed treatment comparisons. Stat Med. 2004 Oct;23(20):3105-24. https://doi.org/10.1002/sim.1875

12. Dias S, Welton NJ, Caldwell DM, Ades AE. Checking consistency in mixed treatment comparison metaanalysis. Stat Med. 2010 Mar;29(7-8):932-44. https://doi.org/10.1002/sim.3767 PMID:20213715
13. Santos MP, Passos M, Luiz RR, Maia LC. A randomized trial of resin-based restorations in class I and class II beveled preparations in primary molars: 24-month results. J Am Dent Assoc. 2009 Feb;140(2):156-66. https://doi.org/10.14219/jada.archive.2009.0129 PMID:19188412

14. Santos MPA, Luiz RR, Maia LC. Randomised trial of resinbased restorations in Class I and Class II beveled preparations in primary molars: 48-month results. J Dent. 2010 Jun;38(6):451-9. https://doi.org/10.1016/j.jdent.2010.02.004

15. Sengul F, Gurbuz T. Clinical evaluation of restorative materials in primary teeth class II lesions. J Clin Pediatr Dent. 2015;39(4):315-21. https://doi.org/10.17796/1053-4628-39.4.315

16. Hse KM, Wei SH. Clinical evaluation of compomer in primary teeth: 1-year results. J Am Dent Assoc. 1997 Aug;128(8):1088-96. https://doi.org/10.14219/jada.archive.1997.0366

17. Marks LA, Amerongen WE, Kreulen CM, Weerheijm KL, Martens LC. Conservative interproximal box-only polyacid modified composite restorations in primary molars, twelve-month clinical results. ASDC J Dent Child. 1999 Jan-Feb;66(1):23-9.

18. Dutta BN, Gauba K, Tewari A, Chawla HS. Silver amalgam versus resin modified $\mathrm{GIC}$ class-II restorations in primary molars: twelve month clinical evaluation. J Indian Soc Pedod Prev Dent. 2001 Sep;19(3):118-22.

19. Andersson-Wenckertl, Sunnegårdh-Grönberg K. Flowable resin composite as a class II restorative in primary molars: A two-year clinical evaluation. Acta Odontol Scand. 2006 Nov;64(6):334-40. https://doi.org/10.1080/00016350600788245

20. Casagrande L, Dalpian DM, Ardenghi TM, Zanatta FB, Balbinot CE, García-Godoy F et al. Randomized clinical trial of adhesive restorations in primary molars. 18-month results. Am J Dent. 2013 Dec;26(6):351-5.

21. Hübel S, Mejàre I. Conventional versus resin-modified glassionomer cement for Class II restorations in primary molars. A 3-year clinical study. Int J Paediatr Dent. 2003 Jan;13(1):2-8. https://doi.org/10.1046/j.1365-263X.2003.00416.x PMID:12542617

22. Tonn EM, Ryge G, Chambers DW. A two-year clinical study of a carvable composite resin used as class II restorations in primary molars. ASDC J Dent Child. 1980 Nov-Dec;47(6):405-13.

23. Oldenburg TR, Vann WF Jr, Dilley DC. Comparison of composite and amalgam in posterior teeth of children. Dent Mater. 1987 Aug;3(4):182-6. https://doi.org/10.1016/S0109-5641(87)80031-3

24. Barr-Agholme M, Odén A, Dahllöf G, Modeér T. A two-year clinical study of light-cured composite and amalgam restorations in primary molars. Dent Mater. 1991 Oct;7(4):230-3. https://doi.org/10.1016/S0109-5641(05)80020-X 
25. Welbury RR, Walls AW, Murray JJ, McCabe JF. The 5 -year results of a clinical trial comparing a glass polyalkenoate (ionomer) cement restoration with an amalgam restoration. Br Dent J. 1991 Mar;170(5):177-81. https://doi.org/10.1038/sj.bdj.4807465

26. Welbury RR, Shaw AJ, Murray JJ, Gordon PH, McCabe JF. Clinical evaluation of paired compomer and glass ionomer restorations in primary molars: final results after 42 months. Br Dent J. 2000 Jul;189(2):93-7. https://doi.org/10.1038/sj.bdj.4800693a •

27. Duggal MS, Toumba KJ, Sharma NK. Clinical performance of a compomer and amalgam for the interproximal restoration of primary molars: a 24-month evaluation. Br Dent J. 2002 Sep;193(6):339-42. https://doi.org/10.1038/sj.bdj.4801560

28. Kavvadia K, Kakaboura A, Vanderas AP, Papagiannoulis L. Clinical evaluation of a compomer and an amalgam primary teeth class II restorations: a 2-year comparative study. Pediatr Dent. 2004 May-Jun;26(3):245-50.

29. Pascon FM, Kantovitz KR, Caldo-Teixeira AS, Borges AF, Silva TN, Puppin-Rontani RM et al. Clinical evaluation of composite and compomer restorations in primary teeth: 24 -month results. J Dent. 2006 Jul;34(6):381-8. https://doi.org/10.1016/i.jdent.2005.08.003

30. Bektas Donmez S, Uysal S, Dolgun A, Turgut MD. Clinical performance of aesthetic restorative materials in primary teeth according to the FDI criteria. Eur J Paediatr Dent. 2016 Sep;17(3):202-12.

31. Daou MH, Tavernier B, Meyer JM. Clinical evaluation of four different dental restorative materials: one-year results. Schweiz Monatsschr Zahnmed. 2008;118(4):290-5.

32. Croll TP, Nicholson JW. Glass ionomer cements in pediatric dentistry: review of the literature. Pediatr Dent. 2002 Sep-Oct;24(5):423-9.

33. Espelid I, Tveit AB, Tornes KH, Alvheim H. Clinical behaviour of glass ionomer restorations in primary teeth. J Dent. 1999 Aug;27(6):437-42. https://doi.org/10.1016/S0300-5712(99)00004-4
34. Chadwick BL, Evans DJ. Restoration of class II cavities in primary molar teeth with conventional and resin modified glass ionomer cements: a systematic review of the literature. Eur Arch Paediatr Dent. 2007 Mar;8(1):14-21. https://doi.org/10.1007/BF03262565

35. Hilgert LA, Amorim RG, Leal SC, Mulder J, Creugers $\mathrm{NH}$, Frencken JE. Is high-viscosity glass-ionomercement a successor to amalgam for treating primary molars? Dent Mater. 2014 Oct;30(10):1172-8. https://doi.org/10.1016/i.dental.2014.07.010

36. Frencken JE, Van 't Hof MA, Van Amerongen WE, Holmgren CJ. Effectiveness of single-surface ART restorations in the permanent dentition: a metaanalysis. J Dent Res. 2004 Feb;83(2):120-3. https://doi.org/10.1177/154405910408300207

37. Tedesco TK, Calvo AF, Lenzi TL, Hesse D, Guglielmi CA, Camargo LB et al. ART is an alternative for restoring occlusoproximal cavities in primary teeth evidence from an updated systematic review and metaanalysis. Int J Paediatr Dent. 2017 May;27(3):201-9. https://doi.org/10.1111/ipd.12252

38. Pinto GS, Oliveira LJ, Romano AR, Schardosim LR, Bonow ML, Pacce $M$ et al. Longevity of posterior restorations in primary teeth: results from a paediatric dental clinic. J Dent. 2014 Oct;42(10):1248-54. https://doi.org/10.1016/i.jdent.2014.08.005

39. Ferracane JL. Resin composite: state of the art. Dent Mater. 2011 Jan;27(1):29-38. https://doi.org/10.1016/j.dental.2010.10.020

40. Tyas MJ, Anusavice KJ, Frencken JE, Mount GJ. Minimal intervention dentistry - a review. FDI Commission Project 1-97. Int Dent J. 2000 Feb;50(1):1-12. https://doi.org/10.1111/j.1875-595X.2000.tb00540.x

41. Cajazeira MR, De Sabóia TM, Maia LC. Influence of the operatory field isolation technique on tooth-colored direct dental restorations. Am J Dent. 2014 Jun;27(3):155-9. 